\title{
Influence of Pore Aperture and Pore Density on Photoelectrochemical Performance of Titanium Dioxide Nano- Porous Thin Films
}

\author{
Li Fei-hui, Gong Yun-lan*, Gao Jing-han \\ Department of Applied Chemistry, College of Biotechnology and Food Science, Tianjin University of \\ Commerce, Tianjin, China, 300134 \\ *E-mail: tjcugyl@126.com
}

doi: $10.20964 / 2019.04 .51$

Received: 14 September 2018 / Accepted: 13 February 2019 / Published: 10 March 2019

\begin{abstract}
In this paper, preparation of titanium dioxide nano-porous thin films was conducted by electrochemical anodic oxidation. Fluorescence spectrometry, UV-vis absorption spectrometry and electrochemical methods, including electrochemical impedance spectroscopy, chronoamperometry and open-circuit potential time curve test, were used to characterize the photoelectrochemical performance of titanium dioxide nano-porous thin films. Effects of the pore structure, such as average aperture and pore density, on the photoelectrochemical performance of titanium dioxide nano-porous thin films were investigated in detail. The results revealed that $\mathrm{TiO}_{2}$ nano-porous thin films showed much better photoelectrochemical properties under the illumination of simulated sunlight. The larger the specific surface area, the better the photoelectrochemical performance. When the average aperture and pore density were $103 \mathrm{~nm}$ and $1 \times 10^{9} \mathrm{~cm}^{-2}, \mathrm{TiO}_{2}$ nano-porous thin film exhibited the optimum photoelectrochemical performance.
\end{abstract}

Keywords: $\mathrm{TiO}_{2}$; nano-porous; average aperture; pore density; anodic oxidation

\section{$\underline{\text { FULL TEXT }}$}

(C) 2019 The Authors. Published by ESG (www.electrochemsci.org). This article is an open access article distributed under the terms and conditions of the Creative Commons Attribution license (http://creativecommons.org/licenses/by/4.0/). 